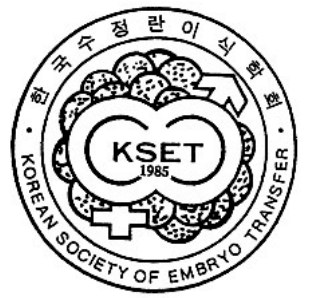

\title{
Pituitary Adenylate Cyclase-activating Polypeptide (PACAP) Treatment during Pre-maturation Increases the Maturation of Porcine Oocytes Derived from Small Follicles
}

\author{
Kyu-Mi Park ${ }^{1,2}$, Kyoung-Ha So ${ }^{1,2,+}$ and Sang-Hwan Hyun ${ }^{1,2,}$ \\ ${ }^{1}$ Institute of Stem Cell \& Regenerative Medicine, Chungbuk National University, 1 Chungdae-ro, \\ Seowon-gu, Cheongiu 28644, Republic of Korea \\ ${ }^{2}$ Laboratory of Veterinary Embryology and Biotechnology, Veterinary Medical Center and \\ College of Veterinary Medicine, Chungbuk National University, 1 Chungdae-ro, Seowon-gu, \\ Cheongju 28644, Republic of Korea;
}

\section{Abstract}

Cellular cyclic adenosine-3' 5'-monophosphate (cAMP) modulator is known as meiotic inhibitor and can delays spontaneous maturation in IVM experiment. Among many cAMP modulators, the role of Pituitary adenylate cyclase activating polypeptide (PACAP) on IVM isn't known. The purpose of this study is to improve the maturation of oocytes derived from follicles $\leq 3 \mathrm{~mm}$ in diameter through PACAP as meiotic inhibitor during pre-in vitro maturation (pre-IVM). First, we checked PACAP and its receptors in cumulus cells and, to establish the optimal phase and concentration of PACAP for pre-IVM, we conducted chromatin configuration assessments. As a result, the rate of GV (Germinal Vesicle) according to duration of pre-IVM was significantly decreased $12 \mathrm{~h}$ and $18 \mathrm{~h}$ after IVM (87.1 and $84.1 \%$, respectively) compared to $0 \mathrm{~h}(99.4 \%)$. When COC was cultured for $18 \mathrm{~h}$, the GV rate in the $1 \mu \mathrm{M}$ of PACAP treatment group (82.1\%) was significantly higher than any other PACAP treatment groups $(60.5,64.1,74.4$ and $69.9 \%$, respectively). So, we divided into four groups as follows; MF (the conventional IVM group, obtained from follicle from 3 to $6 \mathrm{~mm}$ in diameter), SF (the conventional IVM group, obtained from follicle $\leq 3 \mathrm{~mm}$ in diameter), Pre-SF(-)PACAP (IVM group including $18 \mathrm{~h}$ pre-IVM without $1 \mu \mathrm{M}$ of PACAP, obtained from follicle $\leq 3 \mathrm{~mm}$ in diameter) and Pre-SF $(+$ )PACAP (IVM group including $18 \mathrm{~h}$ pre-IVM with $1 \mu \mathrm{M}$ of PACAP, obtained from follicle $\leq 3 \mathrm{~mm}$ in diameter). To examine the effect of PACAP during pre-IVM, we investigated analysis of nuclear maturation, intracellular glutathione (GSH) and reactive oxygen species (ROS) levels. In cumulus cells, PACAP receptors, ADCYAPIR1 and VIPR1 were detected but were not detected in oocytes. After IVM, the Pre-SF(+)PACAP had the highest Metaphase II rate (91.7\%) among all groups $(P<0.05)$. The GSH levels in the MF and Pre-SF $(+)$ PACAP were significantly higher than in the other groups $(P<0.05)$ and ROS levels was no significant difference among all groups. In conclusion, these results indicated that even though the oocytes were derived from SF, pre-IVM application of PACAP improved meiotic and cytoplasmic maturation by regulating intracellular oxidative stress.

Received : 22 December 2017 Revised : 14 February 2018 Accepted : 14 March 2018
Key Words : Porcine, Oocyte, PACAP, Pre-in vitro maturation
† Correspondence: Kyoung-Ha So (ORCID: 0000-0002-1461-0518) Phone: +82-43-249-1845, Fax: +82-43-267-3150 E-mail: khso@cbu.ac.kr
Sang-Hwan Hyun (ORCID: 0000-0001-6011-2555)

Phone: +82-43-261-3393, Fax: +82-43-267-3150

E-mail: shhyun@cbu.ac.kr 


\section{INTRODUCTION}

Mammalian oocytes in the ovarian follicle are arrested at the end of prophase I and resume the first meiotic division after exposure of the follicle to $\mathrm{LH}$ or their isolation from the follicle. Maturing oocytes progress to the second meiotic division and are interrupted at meiotic metaphase II, which is relieved after fertilization (Findlay. 2012). A conventional in vitro maturation (IVM) system to obtain matured oocytes is only appropriate for oocytes obtained from medium (from 3 to $6 \mathrm{~mm}$ in diameter; MF) or large ( $\geq 6 \mathrm{~mm}$ in diameter) follicles, which have the capacity to resume meiosis and support early embryonic development (Wu et al., 2006). However, follicles in large animals comprise a wide range of follicular diameters, particularly many small follicles ( $\leq 3 \mathrm{~mm}$ in diameter; SF) as early antral follicles. When using a standard IVM system, few oocytes derived from SF were able progress to metaphase stage II and had a developmental competence compared with MF (Marchal et al., 2002). And, the growing oocyte isolated from small follicles is unlikely to respond to the gonadotropin surge and may undergo spontaneous meiotic processes without sufficient cytoplasmic maturation (Edwards. 1965).

Among various methods to increase IVM efficiency, pre-IVM application of meiotic inhibitors, including cellular cyclic adenosine-3' 5'-monophosphate (cAMP) modulator, could more adequately mimic in vivo oocyte capacitation (Kwak et al., 2012). As a result, this phase delays spontaneous maturation and stimulates gap-junctional communication between cumulus cells and oocytes (Richani et al., 2014). Nevertheless, the optimal phase of pre-IVM has not been established. When pre-IVM systems during the optimal phase was applied to porcine oocytes, which were derived from small follicles, we proposed that the oocyte synchronizes with nuclear and ooplasmic maturation by inhibition of spontaneous meiotic processes.

Pituitary adenylate cyclase activating polypeptide (PACAP), which increases cellular cyclic adenosine 3'5'-monophosphate (cAMP), is derived from the hypothalamus (Arimura. 2007) and is a member of the vasoactive intestinal peptide (VIP)secretin-glucagon family. PACAP has not only been detected in the central nervous system but also in many peripheral organs, including reproductive and lymphoid organs (Arimura. 1998). PACAP has receptors such as VIPR1, VIPR2 and PAC1; PAC1 binds PACAP with high affinity and VIPR1 and VIPR2 bind VIP and PACAP with equivalent affinity (Sherwood et al., 2000). Indeed, several studies of the role of PACAP in the gonads have implicated PACAP in follicular development Latini et al., 2010), antiapoptotic effects (Morelli et al., 2008) and implantation (Isaac et al., 2008). However, the physiological function of PACAP in mammalian oocyte during meiotic maturation remains unknown.

We hypothesized pre-IVM system using the cAMP modulator PACAP as meiotic and apoptosis inhibitor would improve meiotic and cytoplasmic maturation to oocytes isolated from SF. In the present study, first, PACAP and PACAP receptors expression was revealed on cumulus cells and oocytes. Second, we established an optimal pre-IVM phase and concentration of PACAP by evaluating the germinal vesicle stage. Third, the effects of pre-IVM treatment with PACAP on the maturation of oocyte derived from SF through nuclear maturation and intracellular levels of GSH and ROS was examined.

\section{MATERIALS and METHODS}

\section{Chemicals}

All chemicals and reagents were obtained from Sigma-Aldrich Chemical Company (St. Louis, MO, USA).

\section{Ovary collection and classification}

Ovaries of prepubertal gilts were obtained from a local abattoir and kept in $0.9 \%(\mathrm{w} / \mathrm{v}) \mathrm{NaCl}$ solution between $32^{\circ} \mathrm{C}$ to $35^{\circ} \mathrm{C}$. Cumulus-oocyte complexes (COCs) were aspirated according to their follicle diameter: small ( $\leq 3 \mathrm{~mm})$ and medium $(3-6 \mathrm{~mm})$. The COCs were aspirated using aspiration method. After washing in HEPES-buffered Tyrode's medium (TLH) containing $0.05 \%$ (w/v) polyvinyl alcohol (TLH-PVA), only compact COCs and homogenous cytoplasm were selected and washed three times in TLH-PVA. 


\section{Pre-IVM and Fluorescent staining for assessment of chromatin configuration}

The selected COCs were cultured in a four-well dish (Nunc, Roskilde, Denmark) with pre-IVM media containing $500 \mathrm{ml}$ of culture medium (TCM199; Invitrogen Corporation) supplemented with $0.6 \mathrm{mM}$ cysteine, $0.91 \mathrm{mM}$ sodium pyruvate, $10 \mathrm{ng} / \mathrm{ml}$ of epidermal growth factor, $75 \mu \mathrm{g} / \mathrm{ml}$ of kanamycin and $1 \mu \mathrm{g} / \mathrm{ml}$ of insulin. The duration of the pre-IVM $(0,6,12,18$ and $24 \mathrm{~h})$ was commenced after all COCs were freed from the follicle. Following the pre-IVM period or IVM period respectively, all CCs around the oocytes were denuded by gently pipetting with $0.1 \%$ of hyaluronidase and washed in TLH-PVA. The denuded oocytes were fixed with $1 \%$ of formaldehyde and stained with Hoechst $33342(10 \mu \mathrm{g} / \mathrm{ml})$ for 7 minutes. The stained oocytes were evaluated using fluorescence microscope (TE300, Nikon, Japan) and classified as follows: germinal vesicle (GV), germinal vesicle breakdown (GVBD), metaphase I (MI), anaphase-telophase I (AT-I), or metaphase II (MII) according to meiotic maturation stage. The classification standard is according to the degree of chromatin mass condensation within GV based on previous studies (Dieci et al., 2013). To establish optimal concentration of PACAP, the selected COCs were cultured on IVM medium with PACAP (control, $500 \mathrm{fM}, 100 \mathrm{pM}, 10 \mathrm{nM}$, and $1 \mu \mathrm{M})$. Following the concentration of PACAP during the same pre-IVM period respectively, the oocytes were mechanically denuded from cumulus cells by $0.1 \%$ of hyaluronidase in TLH-PVA and then followed the same steps as above.

\section{In vitro maturation (IVM)}

Approximately 50-60 COCs derived from small follicle were transferred into culture medium as mentioned previously. The COCs were cultured in medium without (Pre-SF(-)PACAP group) or with $1 \mu \mathrm{M}$ PACAP (Pre-SF(+)PACAP group) and placed at $39^{\circ} \mathrm{C}$ with of $5 \% \mathrm{CO}_{2}$ in air for $18 \mathrm{~h}$ of the pre-IVM period. Following the pre-IVM period, COCs were washed twice in the conventional IVM medium containing $10 \%(\mathrm{v}: \mathrm{v})$ porcine follicular fluid in pre-IVM medium. Then, 60 of COCs derived from medium follicle (MF group; control), small follicle (SF group) and Pre-matured groups were cultured with supplement containing $10 \mathrm{IU} / \mathrm{ml}$ of eCG and $10 \mathrm{IU} / \mathrm{ml}$ of $\mathrm{hCG}$ at $39^{\circ} \mathrm{C}$ and $5 \% \mathrm{CO}_{2}$. The COCs were maturated with or without hormones IVM medium for 20 to 22 hours each.

\section{Evaluation of nuclear maturation}

For the analyze of nuclear maturation after IVM, metaphase II (M II) stage of oocytes were stained and evaluated almost the same as for the assessment of chromatin configuration. After COCs were denuded by gently pipetting with $0.1 \%$ of hyaluronidase, the denuded oocytes washed in TLH-PVA and fixed with $1 \%$ of formaldehyde and stained with Hoechst 33342 (10 $\mu \mathrm{g} / \mathrm{ml})$ for 7 minutes. The stained oocytes were evaluated using fluorescence microscope (TE300, Nikon, Japan) and classified as GV, GVBD, MI, AT-I and MII according to meiotic maturation stage.

\section{Measurement of intracellular ROS and GSH levels}

After IVM of oocytes, intracellular GSH and ROS levels were determined. Glutathione and ROS level assessments were carried out as previously described (Cheng et al., 2004; You et al., 2010). Briefly, 2',7'-dichlorodihydrofluorescein diacetate (H2DCFDA; Invitrogen Corporation) and 4-chloromethyl-6.8-difluoro-7-hydroxycoumarin (Cell Tracker Blue; Invitrogen Corporation) were used to detect intracellular ROS levels as green fluorescence and GSH levels as blue fluorescence, respectively. The matured oocytes from each group were treated with TLH-PVA and then incubated with $10 \mu \mathrm{M}$ of H2DCFDA and $10 \mu \mathrm{M}$ of Cell Tracker Blue for 30 minutes in the darkroom. After incubation, the oocytes were washed with DPBS containing $0.1 \%$ (w/v) PVA and fluorescence was observed using an epifluorescence microscope (TE300; Nikon, Japan) with UV filters (460 nm and $370 \mathrm{~nm}$ for ROS and GSH respectively). Fluorescent images were saved as graphic files in JEPG format and then the intensity of oocytes was measured by Adobe Photoshop CS3 software (Version 10.0, San Jose, CA, USA) and normalized to control oocytes. The experiment was replicated three times. 


\section{Reverse transcription polymerase chain reaction analysis (RT-PCR)}

Trizol reagent (Invitrogen, CA, USA) was used for total RNA extraction from matured cumulus cells and oocytes. To produce cDNA, RNA was transcribed by Moloney murine leukemia virus (MMLV) reverse transcriptase with random primer. Each cDNA was used as template and mixed with primers and $\mathrm{H}_{2} \mathrm{O}$ that primers information is described at Table 1. Polymerase chain reaction amplification is carried out by 40 cycles of $30 \mathrm{sec}$ at $95^{\circ} \mathrm{C}, 30 \mathrm{sec}$ at $58^{\circ} \mathrm{C}, 30 \mathrm{sec}$ at $72^{\circ} \mathrm{C}$. And then, product was confirmed by electrophoresis using $1.5 \%$ of agarose gel. As a size maker, DNA molecular weight 100-bp ladder (Mannheim, Germany) was used.

Table 1. Primer Sequences for analysis of mRNA gene expression.

\begin{tabular}{|c|c|c|c|}
\hline Gene Name & Primer sequences & $\begin{array}{l}\text { Product size } \\
\text { (base pairs) }\end{array}$ & Gene Bank Accession number \\
\hline$A D C Y A P 1(\mathrm{PACAP})$ & $\begin{array}{l}\text { F: 5'-TACTACCCAGCGGAAGAAAG-3' } \\
\text { R: 5'-TAGCTGTCCGTGAAGATTCC-3' }\end{array}$ & 200 & NM_001001544 \\
\hline VIPRl & $\begin{array}{l}\text { F: 5'-TACCACCATCTCTGCAACC-3' } \\
\text { R: 5'-ATTATTGCACCAGCCTGTTT-3' }\end{array}$ & 200 & NM_214036 \\
\hline $\operatorname{VIPR} 2$ & $\begin{array}{l}\text { F: 5'-GGTGGCTGTTCTCTACTGCT-3' } \\
\text { R: 5'-AGATGACCGAGGTCTCCAT-3' }\end{array}$ & 206 & NM_0011955117 \\
\hline$A D C Y A P 1 R 1(\mathrm{PAC} 1)$ & $\begin{array}{l}\text { F: 5'-GGTGGCTGTTCTCTACTGCT-3' } \\
\text { R: 5'-GGATCTGGGAACTGCTCTT-3' }\end{array}$ & 185 & NM_001199808 \\
\hline$G A P D H$ & $\begin{array}{l}\text { F: 5'-GTCGGTTGTGGATCTGACCT-3' } \\
\text { R: 5'-TTGACGAAGTGGTCGTTGAG-3' }\end{array}$ & 207 & NM_001206359 \\
\hline
\end{tabular}

\section{Experimental design}

In experiment 1, the expression of PACAP and its receptors in cumulus cells and oocytes was carried out by RT-PCR. In experiment 2, the effect of treatment with various pre-IVM duration $(0,6,12,18$ and $24 \mathrm{~h}$ ) and concentration of PACAP (control, $500 \mathrm{fM}, 100 \mathrm{pM}, 10 \mathrm{nM}, 1 \mu \mathrm{M})$ on nuclear maturation was examined to identify the optimal concentration and duration for delay of spontaneous meiotic processes. In experiment 3, the effect of pre-IVM with PACAP treatment on nuclear maturation and intracellular levels of GSH and ROS was investigated.

\section{Statistical analysis}

Statistical analyses were done through SPSS 17.0 (SPSS, Inc., Chicago, IL, USA). A one-way ANOVA with Duncan's multiple range test was used to assess percentage data of rates of maturation and levels of GSH and ROS. Data are presented as the mean \pm SEM. Differences at $P<0.05$ were considered significant, unless otherwise stated.

\section{RESULTS}

\section{Expression of PACAP and its receptor into the cumulus cells and oocytes.}

Expression of PACAP (ADCYAP1) and its receptors such as ADCYAP1R1(PAC1), VPAC1, and VIPR2 into the cumulus cells and oocytes was detected by RT-PCR. As shown in Figure 1, ADCYAP1Rl(PAC1) and VPACl were expressed in cumulus cells but not in oocytes. GAPDH is used as a control. 


\section{Cumulus cells}

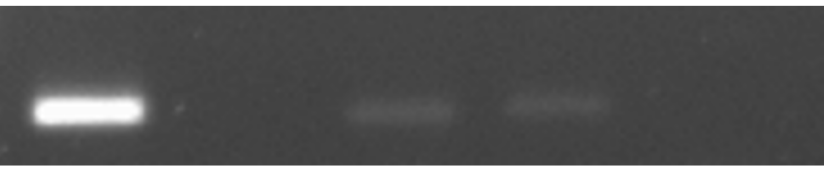

\section{7 bp}

Oocytes

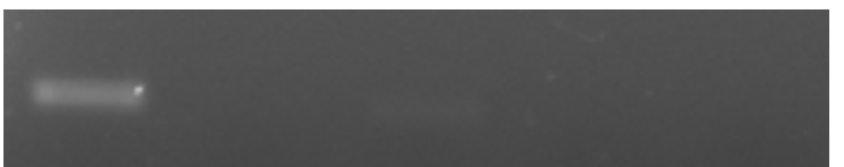

\section{7 bp}

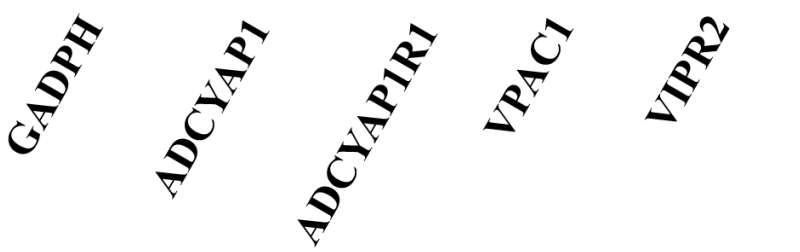

Figure 1. Identification of PACAP (ADCYAP1) and its receptors in the cumulus cells and oocytes by reverse transcription polymerase chain reaction (RT-PCR). GAPDH is used as control.

\section{Establishment of the optimal pre-IVM duration}

In the first set of experiments, we determined the time and concentration of PACAP that could prevent germinal vesicle breakdown (GVBD) in oocytes. COCs derived from SF were cultured for varying periods (0, 6, 12, 18 and 24 h). We aimed to delay GVBD of oocytes. As shown in Table 2, not only the rate of GVBD in these groups, except the 0 and $24 \mathrm{~h}$ groups, but also the rate of germinal vesicle $(\mathrm{GV})$ between the 12 and $18 \mathrm{~h}$ groups showed no statistical significance. The GV rate for the $24 \mathrm{~h}$ groups rapidly decreased compared with those of the 12 and $18 \mathrm{~h}$ groups $(P<0.05)$. Thus, we set the pre-IVM phase at $18 \mathrm{~h}$. COCs derived from SF were cultured in media supplemented with increasing concentrations of PACAP $(0,500 \mathrm{fM}, 100$ $\mathrm{pM}, 10 \mathrm{nM}$ and $1 \mu \mathrm{M}$ ) during $18 \mathrm{~h}$. As shown in Table 3, when COC was cultured for $18 \mathrm{~h}$, the GV rate in the $1 \mu \mathrm{M}$ of PACAP treatment group was higher than the other PACAP treatment groups $(P<0.05)$. Based on these results, $1 \mu \mathrm{M}$ PACAP was treated at Pre-IVM for $18 \mathrm{~h}$.

Table 2. Nuclear status of porcine oocytes according to time of in vitro maturation.

\begin{tabular}{|c|c|c|c|c|c|c|}
\hline & \multirow{2}{*}{ Type } & \multirow{2}{*}{$\begin{array}{c}\text { No. of oocytes } \\
\text { cultured for IVM }\left(3^{*}\right)\end{array}$} & \multicolumn{4}{|c|}{ No. $(\%)$ of oocytes at the stage of } \\
\hline & & & GV & GVBD & M I & A I / T I /M II \\
\hline \multirow{5}{*}{ Pre-IVM } & $0 \mathrm{~h}$ & 167 & $166(99.4 \pm 0.6)^{\mathrm{c}}$ & $1(0.6 \pm 0.6)^{\mathrm{a}}$ & $0(0)^{\mathrm{a}}$ & $0(0)^{\mathrm{a}}$ \\
\hline & $6 \mathrm{~h}$ & 188 & $182(96.8 \pm 0.9)^{\mathrm{c}}$ & $5(2.6 \pm 1.4)^{\mathrm{a}, \mathrm{b}}$ & $1(0.5 \pm 0.5)^{\mathrm{a}, \mathrm{b}}$ & $0(0)^{\mathrm{a}}$ \\
\hline & $12 \mathrm{~h}$ & 180 & $157(87.2 \pm 1.1)^{\mathrm{b}}$ & $14(7.9 \pm 2.4)^{\mathrm{a}, \mathrm{b}}$ & $9(4.8 \pm 1.7)^{\mathrm{b}}$ & $0(0)^{\mathrm{a}}$ \\
\hline & $18 \mathrm{~h}$ & 177 & $149(84.1 \pm 2.3)^{\mathrm{b}}$ & $7(4.1 \pm 2.1)^{\mathrm{a}, \mathrm{b}}$ & $17(9.6 \pm 2.4)^{\mathrm{c}}$ & $4(2.2 \pm 2.2)^{\mathrm{a}}$ \\
\hline & $24 \mathrm{~h}$ & 187 & $121(64.9 \pm 0.8)^{\mathrm{a}}$ & $20(11.1 \pm 4.9)^{\mathrm{b}}$ & $25(13.4 \pm 0.9)^{\mathrm{c}}$ & $20(10.6 \pm 5.3)^{b}$ \\
\hline
\end{tabular}

The date is mean \pm SEM

* Replication number

a,b,c Values with different superscripts with a column were different $(p<0.05)$.

Abbreviation: A I /T I /M II, anaphase I / telophase I / metaphase II; GV, germinal vesicle; GVBD, germinal vesicle breakdown; M I, metaphase I 
Table 3. Effect of Pre-IVM with PACAP treatment on nuclear status depending on $18 \mathrm{~h}$.

\begin{tabular}{cccccc}
\hline \multirow{2}{*}{$\begin{array}{c}\text { PACAP* } \\
\text { Concentration }\end{array}$} & $\begin{array}{c}\text { No. of oocytes cultured } \\
\text { for IVM }\left(3^{* *}\right)\end{array}$ & GV & No. (\%) of oocytes at the stage of \\
\cline { 3 - 6 } 0 & 114 & $68(60.5 \pm 1.3)^{\mathrm{a}}$ & $32(28.3 \pm 2.3)^{\mathrm{b}}$ & $8(6.9 \pm 1.3)^{\mathrm{a}, \mathrm{b}}$ & $5(4.3 \pm 0.7)^{\mathrm{b}}$ \\
$500 \mathrm{fM}$ & 115 & $74(64.1 \pm 2.4)^{\mathrm{a}}$ & $20(17.8 \pm 5.5)^{\mathrm{a}}$ & $16(13.7 \pm 2.9)^{\mathrm{b}}$ & $5(4.3 \pm 0.7)^{\mathrm{b}}$ \\
$100 \mathrm{pM}$ & 109 & $81(74.4 \pm 0.8)^{\mathrm{b}}$ & $13(11.7 \pm 2.8)^{\mathrm{a}}$ & $12(11.3 \pm 2.3)^{\mathrm{b}}$ & $3(2.6 \pm 1.4)^{\mathrm{a}, \mathrm{b}}$ \\
$10 \mathrm{nM}$ & 119 & $83(69.9 \pm 1.8)^{\mathrm{b}}$ & $21(17.6 \pm 0.8)^{\mathrm{a}}$ & $12(10 \pm 1.1)^{\mathrm{a}, \mathrm{b}}$ & $3(2.5 \pm 0.1)^{\mathrm{a}, \mathrm{b}}$ \\
$1 \mu \mathrm{M}$ & 117 & $96(82.1 \pm 1.2)^{\mathrm{c}}$ & $16(13.7 \pm 2.3)^{\mathrm{a}}$ & $4(3.4 \pm 2.2)^{\mathrm{a}}$ & $1(0.8 \pm 0.8)^{\mathrm{a}}$ \\
\hline
\end{tabular}

The date is mean \pm SEM

* pituitary adenylate cyclase activating polypeptide

** Replication number

a,b,c Values with different superscripts with a column were different $(p<0.05)$.

Abbreviation: A I /T I /M II, anaphase I / telophase I / metaphase II; GV, germinal vesicle; GVBD, germinal vesicle breakdown; M I, metaphase I

\section{Effect of Pre-IVM with PACAP on nuclear and cytoplasmic maturation during IVM}

We evaluated the MII stage to analyse nuclear maturation at the end of the culture periods. As shown in Table 4, the rates of oocytes reaching MII were significantly higher in oocytes from the Pre-SF(+)PACAP group than those from the other groups $(P<0.05)$. The GV rates of the Pre-IVM treatment groups were significantly lower than those of the MF and SF groups $(P<0.05)$. To assess cytoplasmic maturation, we examined the intracellular GSH and ROS levels in MII oocytes. As shown in Figure 2, the intracellular GSH levels of oocytes were significantly increased $(P<0.05)$ in the Pre-SF $(+)$ PACAP and MF groups compared with the Pre-SF(-)PACAP and SF groups. There were no significant differences in ROS levels.

Table 4. Effect of Pre-IVM with PACAP treatment on nuclear maturation in porcine oocytes.

\begin{tabular}{|c|c|c|c|c|c|}
\hline \multirow{2}{*}{ Type } & \multirow{2}{*}{$\begin{array}{c}\text { No. of oocytes } \\
\text { cultured for IVM } \\
\left(3^{*}\right)\end{array}$} & \multicolumn{4}{|c|}{ No. $(\%)$ of oocytes at the stage of } \\
\hline & & GV & M I & A I /T I & M II \\
\hline MF & 142 & $17(12 \pm 0.6)^{b}$ & $6(4.2 \pm 1.2)^{\mathrm{a}}$ & $3(2.2 \pm 2.2)$ & $116(81.7 \pm 1)^{b}$ \\
\hline SF & 173 & $31(17.9 \pm 3)^{\mathrm{c}}$ & $16(9.2 \pm 1.2)^{\mathrm{b}}$ & $8(4.6 \pm 1.5)$ & $118(68.2 \pm 1.9)^{\mathrm{a}}$ \\
\hline Pre-SF(-)PACAP & 169 & $10(5.9 \pm 1.2)^{\mathrm{a}}$ & $16(9.4 \pm 1.1)^{\mathrm{b}}$ & $5(3 \pm 0.6)$ & $138(81.7 \pm 0.5)^{\mathrm{b}}$ \\
\hline Pre-SF(+)PACAP & 168 & $3(1.8 \pm 1)^{\mathrm{a}}$ & $7(4.2 \pm 2.1)^{\mathrm{a}}$ & $4(2.3 \pm 1.6)$ & $154(91.7 \pm 0.4)^{\mathrm{c}}$ \\
\hline
\end{tabular}

The data are mean \pm SEM

* Replication number

a,b,c Values with different superscripts with a column were different $(p<0.05)$

Abbreviation: A I /T I, anaphase I /telophase I; GV, germinal vesicle; M I, metaphase I; M II, metaphase II 
(A)
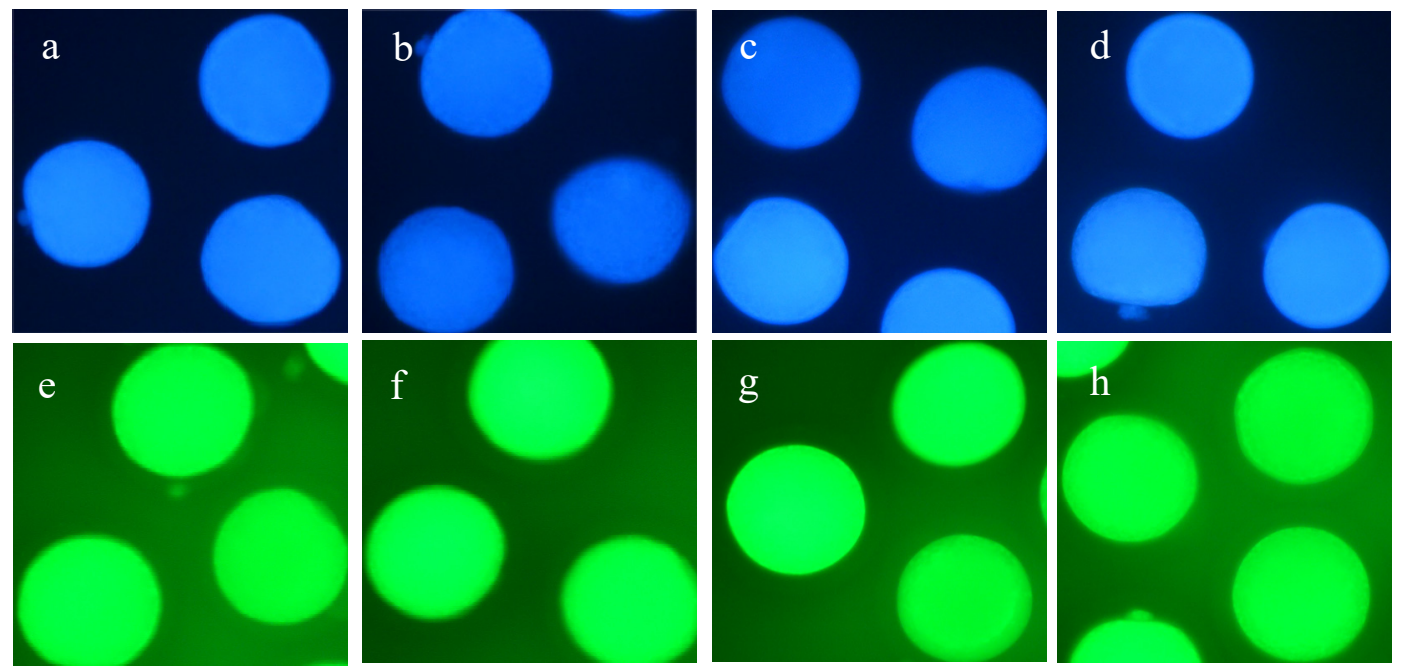

(B)

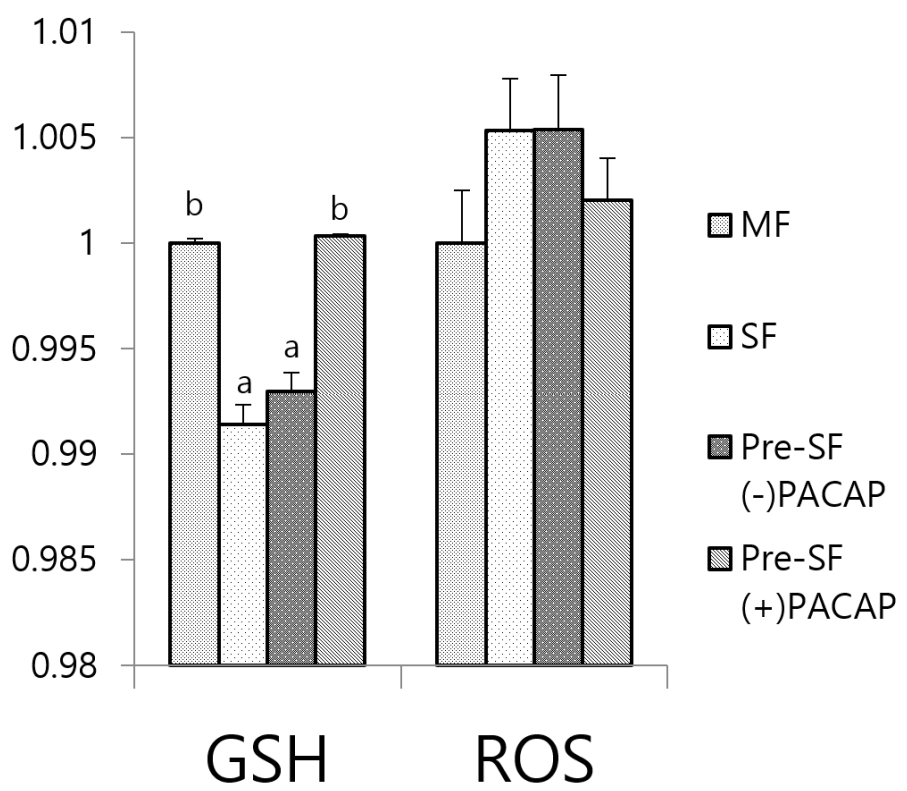

Figure 2. Epifluorescent photomicrographic images of in vitro matured porcine oocytes. (A) Oocytes were stained with Cell Tracker Blue (a-d) and 2', 7'- dihlorodihydrofluorescein diacetate (H2DCFDA) (e-h). Metaphase II (MII) oocytes from medium follicles (MF) $(a, e)$, small follicles (SF) $(b, f)$, pre-SF(-)PACAP $(c, g)$ or Pre-SF(+)PACAP $1 \mu \mathrm{M}(\mathrm{d}, \mathrm{h})$. (B) Effect of pre-maturation with PACAP treatment on the intracellular GSH and ROS levels in porcine oocytes matured in vitro. GSH samples, $N=30$; ROS samples, $N=36$. This experiment was replicated three times. a,b Values with different superscripts with a column were different $(p<0.05)$.

\section{DISCUSSION}

In the present study, we detected the expression of $P A C A P$ and its receptors in cumulus cells and oocytes. Expression of $P A C 1$ and VIPR1 in its receptors was observed only in cumulus cells. However, according to a previous report, VIPR2 as well as PAC1 expression were confirmed in the granulosa cells and matured oocytes in rat (Vaccari et al., 2006). It is found that expression of PACAP and its receptor is influenced by hormone stimulation, species and follicle development (Ko et al., 2000; Park et al., 
2000). When PACAP binds to its receptor, intracellular cAMP increase is induced. Generally, cAMP derived from cumulus cell via gap junctions is transferred to the oocyte and that is crucial for preventing spontaneous maturation (Eppig et al., 1983). Also, PACAP via PAC1 promotes activation of ERK1/2, which induce expression of matrix-related genes (Shimada et al., 2006; Shioda et al., 2016). Cumulus expansion induced by these genes affect oocyte maturity and developmental competence (Chen et al., 1990; Gutnisky et al., 2007). Therefore, as suggested in previous studies, the present study also show that PACAP treatment during pre-IVM prevent spontaneous maturation and improve meiotic and cytoplasmic maturity as a result.

In the present study, we evaluated the meiotic kinetics of oocytes derived from SF according to the Pre-IVM culturing time and the concentration of PACAP. The results showed that the kinetics of oocyte meiotic resumption rapidly changed after maturation for $18 \mathrm{~h}$. As shown in Table 2, the rate of GV after $24 \mathrm{~h}$ is $64.9 \%$, but Park et al (Park et al., 2016) showed that the rate of GV after $24 \mathrm{~h}$ was only $20.6 \%$ using oocytes derived from MF. Thus, the spontaneous maturation of oocyte is related to the follicle size. This finding was inconsistent with that of a previous study showing that the incidences of maturation for oocytes from various follicle sizes have no significant difference on the first meiotic division, except for oocytes from large follicles (McGaughey et al., 1979). These conflicting results could reflect the composition and formulation of the employed oocyte IVM media. The GV rate in $18 \mathrm{~h}$ pre-IVM differ between Table $2(84.1 \%)$ and Table $3(60.5 \%)$ due to the prolonged denuding time caused by a higher number of oocytes being used for the experiments. This result was consistent with previously published study showing that spontaneous oocyte maturation could result from the stress related to the artificial environment. Even with the difference of the GV rate between Table 2 and Table 3 on $18 \mathrm{~h}$ pre-IVM, each experiment group was conducted under the same condition so the result is comparable within the group. The results of Table 3 indicate that the proportion of oocytes in the GV stage increased depending on the dose of PACAP as cAMP modulator. However, previous studies have reported that it is not clear whether the presence of a high cAMP concentration is effective for meiotic arrest (Conti et al., 2002). And, little is known about the actions of PACAP in follicular fluid (FF), where the concentration of PACAP in FF is only about fmol/ml. Therefore, we treated $1 \mathrm{uM}$ of PACAP for pre-IVM without additional experiment for the higher concentration of PACAP. Previous studies have shown a correlation between the PACAP concentration in FF and number of matured oocytes (Koppan et al., 2012). The high PACAP concentration in FF might correlate to a low oocyte number, while the low PACAP concentration might correlate with a higher number of retrieved oocytes. As shown in previous studies, PACAP affects oocyte physiology. In rats, it is described that PACAP inhibits or accelerates meiotic maturation in oocytes according to the presence of enclosed cumulus (Apa et al., 1997). But, in mouse, it is reported that meiotic maturation was severely impaired by PACAP treatment (Cecconi et al., 2004). Here, we demonstrated that PACAP could act as a meiotic inhibitor for pre-IVM even though effect of PACAP on IVM have contradictory aspects.

In the present study, oocytes cultured with $1 \mu \mathrm{M}$ of PACAP during Pre-IVM showed significantly improved nuclear maturation, although they were isolated from SF. The meiotic competence of oocytes derived from follicles of various follicular sizes has been previously reported with conflicting results. Both of the present and previous studies, the blocking rate of meiotic resumption in oocytes collected from SF was higher compared with that of oocytes derived from MF (Marchal et al., 2002). And, in contrast with our result, several previous studies have reported that the rate of first polar body extrusion in pre-IVM group using cAMP modulator is not significant compared with the control group (Zeng et al., 2014; Li et al., 2016). In comparison with previous reports, our results indicate that PACAP is an effective supplement to improve oocyte maturation during Pre-IVM.

In the present study, the intracellular content of GSH is an important marker indicating oocyte cytoplasmic maturation and embryonic development competence. Increased intracellular GSH protects cells from oxidative damage and improves oocyte cytoplasmic maturation. Thus, the intracellular level of GSH may show differences according to follicle size. Nevertheless, we demonstrated that treatment with $1 \mu \mathrm{M}$ of PACAP during Pre-IVM may improve the cytoplasmic maturation of SF-derived oocytes compared to MF-derived oocytes. As mentioned before, delayed meiosis though the addition of exogenous factors has previously been shown to have beneficial effects on cytoplasmic maturation and embryonic development competence (Coy et al., 2005). However, not all cAMP modulator treatments influence GSH levels in oocytes. In case of pre-IVM using IBMX, no significant difference in the GSH concentration in oocytes was observed between the treatment group and control group (Kwak et al., 2012). Additionally, the intracellular GSH level after $24 \mathrm{~h}$ of Pre-IVM was significantly higher in the control than in the 
cilostamide-treated group (Park et al., 2016). Unlike GSH, the production of intracellular ROS can induce oxidative stress and cellular damage. In the present study, no significant difference in ROS levels was observed. However, prolonging the period of meiotic arrest under in vitro conditions may generally increase oxidative stress. To defend against oxidative stress, the GSH precursor cysteine is commonly added to maturation medium. If the balance of pro-/antioxidants is optimal and maintained, it is conceivable that the activity of ROS is maintained at a normal balance (Combelles et al., 2009). Therefore, it is assumed that the ROS level have no significant influence, even though the period of IVM is prolonged.

In conclusion, Pre-IVM using PACAP was beneficial for meiotic and cytoplasmic maturation of oocytes derived from SF by increasing intracellular GSH level and inhibiting spontaneous maturation. Therefore, the present results suggest that when 1uM PACAP is supplemented during $18 \mathrm{~h}$ as Pre-IVM, the quality of oocytes is improved even though porcine oocytes are originated from SF.

\section{ACKNOWLEDGEMENTS}

This work was supported, in part, by a grant through the "the National Research Foundation of Korea (NRF) funded by the Ministry of Science and ICT (MIST) (NRF-2015H1D3A1066-175, NRF-2016R1D1A1B03933191, NRF-2017R1A2B4002546, NRF-2017K1A4A3014959)" and "Korea Institute of Planning and Evaluation for Technology in Food, Agriculture, Forestry and Fisheries (IPET) through Advanced Production Technology Development Program, funded by Ministry of Agriculture, Food and Rural Affairs (MAFRA) (Grant No. 115103-02)", Republic of Korea.

\section{REFERENCES}

Apa, R., Lanzone, A., Mastrandrea, M., Miceli, F., Macchione, E., Fulghesu, A.M., Caruso, A., Canipari, R., 1997. Effect of pituitary adenylate cyclase-activating peptide on meiotic maturation in follicle-enclosed, cumulus-enclosed, and denuded rat oocytes. Biology of reproduction 57, 1074-1079.

Arimura, A., 1998. Perspectives on pituitary adenylate cyclase activating polypeptide (PACAP) in the neuroendocrine, endocrine, and nervous systems. The Japanese journal of physiology 48, 301-331.

Arimura, A., 2007. PACAP: the road to discovery, Elsevier.

Cecconi, S., Rossi, G., Barberi, M., Scaldaferri, L., Canipari, R., 2004. Effect of pituitary adenylate cyclase-activating polypeptide and vasoactive intestinal polypeptide on mouse preantral follicle development in vitro. Endocrinology 145, 2071-2079.

Chen, L., Wert, S.E., Hendrix, E.M., Russell, P.T., Cannon, M., Larsen, W.J., 1990. Hyaluronic acid synthesis and gap junction endocytosis are necessary for normal expansion of the cumulus mass. Molecular reproduction and development 26, $236-247$.

Cheng, T., Huang, C., Huang, L., Chen, C., Lee, M., Liu, J., 2004. Evaluation of mouse blastocyst implantation rate by morphology grading. Chinese Journal of Physiology 47, 43.

Combelles, C.M., Gupta, S., Agarwal, A., 2009. Could oxidative stress influence the in-vitro maturation of oocytes? Reproductive biomedicine online $18,864-880$.

Conti, M., Andersen, C.B., Richard, F., Mehats, C., Chun, S.-Y., Horner, K., Jin, C., Tsafriri, A., 2002. Role of cyclic nucleotide signaling in oocyte maturation. Molecular and cellular endocrinology 187, 153-159.

Coy, P., Romar, R., Ruiz, S., Cánovas, S., Gadea, J., Vázquez, F.G., Matás, C., 2005. Birth of piglets after transferring of in vitro-produced embryos pre-matured with R-roscovitine. Reproduction 129, 747-755.

Dieci, C., Lodde, V., Franciosi, F., Lagutina, I., Tessaro, I., Modina, S.C., Albertini, D.F., Lazzari, G., Galli, C., Luciano, A.M., 2013. The effect of cilostamide on gap junction communication dynamics, chromatin remodeling, and competence acquisition in pig oocytes following parthenogenetic activation and nuclear transfer. Biology of reproduction 89.

Edwards, R., 1965. Maturation in vitro of mouse, sheep, cow, pig, rhesus monkey and human ovarian oocytes. Nature 208, 
349-351.

Eppig, J.J., Freter, R.R., Ward-Bailey, P.F., Schultz, R.M., 1983. Inhibition of oocyte maturation in the mouse: participation of cAMP, steroid hormones, and a putative maturation-inhibitory factor. Developmental biology 100, 39-49.

Findlay, J.K., 2012. Molecular biology of the female reproductive system. Elsevier.

Gutnisky, C., Dalvit, G.C., Pintos, L.N., Thompson, J.G., Beconi, M.T., Cetica, P.D., 2007. Influence of hyaluronic acid synthesis and cumulus mucification on bovine oocyte in vitro maturation, fertilisation and embryo development. Reproduction, Fertility and Development 19, 488-497.

Isaac, E.R., Sherwood, N.M., 2008. Pituitary adenylate cyclase-activating polypeptide (PACAP) is important for embryo implantation in mice. Molecular and cellular endocrinology 280, 13-19.

Ko, C., Park-Sarge, O.-K., 2000. Progesterone receptor activation mediates LH-induced type-I pituitary adenylate cyclase activating polypeptide receptor (PAC1) gene expression in rat granulosa cells. Biochemical and biophysical research communications 277 , 270-279.

Koppan, M., Varnagy, A., Reglodi, D., Brubel, R., Nemeth, J., Tamas, A., Mark, L., Bodis, J., 2012. Correlation between oocyte number and follicular fluid concentration of pituitary adenylate cyclase-activating polypeptide (PACAP) in women after superovulation treatment. Journal of Molecular Neuroscience 48, 617-622.

Kwak, S.-S., Jang, S.-H., Jeong, S.-H., Jeon, Y., Biswas, D., Hyun, S.-H., 2012. The Effects of 3-Isobutyl-1-methylxanthine (IBMX) on Nuclear and Cytoplasmic Maturation of Porcine Oocytes In Vitro. Journal of Embryo Transfer 27, 163-169.

Latini, S., Chiarpotto, M., Muciaccia, B., Vaccari, S., Barberi, M., Guglielmo, M.C., Stefanini, M., Cecconi, S., Canipari, R., 2010. Inhibitory effect of pituitary adenylate cyclase activating polypeptide on the initial stages of rat follicle development. Molecular and cellular endocrinology 320, 34-44.

Li, H., Sutton-McDowall, M., Wang, X., Sugimura, S., Thompson, J., Gilchrist, R., 2016. Extending prematuration with cAMP modulators enhances the cumulus contribution to oocyte antioxidant defence and oocyte quality via gap junctions. Human Reproduction 31, 810-821.

Marchal, R., Vigneron, C., Perreau, C., Bali-Papp, A., Mermillod, P., 2002. Effect of follicular size on meiotic and developmental competence of porcine oocytes. Theriogenology 57, 1523-1532.

McGaughey, R.W., Montgomery, D.H., Richter, J.D., 1979. Germinal vesicle configurations and patterns of polypeptide synthesis of porcine oocytes from antral follicles of different size, as related to their competency for spontaneous maturation. Journal of Experimental Zoology Part A: Ecological Genetics and Physiology 209, 239-253.

Morelli, M.B., Barberi, M., Gambardella, A., Borini, A., Cecconi, S., Coticchio, G., Canipari, R., 2008. Characterization, expression, and functional activity of pituitary adenylate cyclase-activating polypeptide and its receptors in human granulosa-luteal cells. The Journal of Clinical Endocrinology \& Metabolism 93, 4924-4932.

Park, B., Lee, H., Lee, Y., Elahi, F., Lee, J., Lee, S.T., Park, C.-K., Hyun, S.-H., Lee, E., 2016. Cilostamide and forskolin treatment during pre-IVM improves preimplantation development of cloned embryos by influencing meiotic progression and gap junction communication in pigs. Theriogenology 86, 757-765.

Park, H.-J., Lee, J., Wang, L., Park, J.-H., Kwon, H.-B., Arimura, A., Chun, S.-Y., 2000. Stage-specific expression of pituitary adenylate cyclase-activating polypeptide type I receptor messenger ribonucleic acid during ovarian follicle development in the rat. Endocrinology 141, 702-709.

Richani, D., Wang, X., Zeng, H., Smitz, J., Thompson, J., Gilchrist, R., 2014. Pre maturation with cAMP modulators in conjunction with EGF like peptides during in vitro maturation enhances mouse oocyte developmental competence. Molecular reproduction and development $81,422-435$.

Sherwood, N.M., Krueckl, S.L., McRory, J.E., 2000. The origin and function of the pituitary adenylate cyclase-activating polypeptide (PACAP)/glucagon superfamily. Endocrine Reviews 21, 619-670.

Shimada, M., Hernandez-Gonzalez, I., Gonzalez-Robayna, I., Richards, J.S., 2006. Paracrine and autocrine regulation of epidermal growth factor-like factors in cumulus oocyte complexes and granulosa cells: key roles for prostaglandin synthase 2 and progesterone receptor. Molecular Endocrinology 20, 1352-1365. 
Shioda, S., Takenoya, F., Wada, N., Hirabayashi, T., Seki, T., Nakamachi, T., 2016. Pleiotropic and retinoprotective functions of PACAP. Anatomical science international 91, 313-324.

Vaccari, S., Latini, S., Barberi, M., Teti, A., Stefanini, M., Canipari, R., 2006. Characterization and expression of different pituitary adenylate cyclase-activating polypeptide/vasoactive intestinal polypeptide receptors in rat ovarian follicles. Journal of endocrinology 191, 287-299.

Wu, D., Cheung, Q.C.-K., Wen, L., Li, J., 2006. A growth-maturation system that enhances the meiotic and developmental competence of porcine oocytes isolated from small follicles. Biology of reproduction 75, 547-554.

You, J., Kim, J., Lim, J., Lee, E., 2010. Anthocyanin stimulates in vitro development of cloned pig embryos by increasing the intracellular glutathione level and inhibiting reactive oxygen species. Theriogenology 74, 777-785.

Zeng, H.-T., Richani, D., Sutton-McDowall, M.L., Ren, Z., Smitz, J.E., Stokes, Y., Gilchrist, R.B., Thompson, J.G., 2014. Prematuration with cyclic adenosine monophosphate modulators alters cumulus cell and oocyte metabolism and enhances developmental competence of in vitro-matured mouse oocytes. Biology of reproduction 91. 
